\title{
Progresso Científico e Verdade em Popper
}

\author{
Elizabeth de Assis Dias ${ }^{l}$
}

\begin{abstract}
RESUMO: O presente trabalho pretende mostrar que, para solucionar a questão da possibilidade do progresso científico, Popper precisou introduzir a ideia de verdade no âmbito de sua teoria da ciência. Essa concepção de progresso, em termos da noção de verdade, só será delineada na obra Conjectura e refutaçôes (1963), pois a ideia de que o alvo da ciência é a verdade ainda não aparece teorizada em suas primeiras obras. Quando Popper escreveu sua A lógica da pesquisa científica (1934), a ciência era definida em termos de regras lógico-metodológicas e não de suas metas. $\mathrm{O}$ avanço científico é concebido a partir das noçóes de testabilidade e de corroborabilidade das teorias, exigências lógicometodológicas para que uma teoria seja considerada como científica. Popper não relacionou a questão do progresso científico à noção de verdade, nessa obra, porque, quando a escreveu, não dispunha de uma consistente teoria da verdade. Foi somente após Tarski ter escrito seu artigo sobre a concepçáo semântica da verdade que Popper, tendo por base essa concepção de verdade, pôde complementar as suas teses sobre o progresso da ciência, expostas em sua $A$ lógica da pesquisa cientifica, com uma teoria acerca do conteúdo de verdade e da aproximação da verdade.
\end{abstract}

PALAVRAS-CHAVE: Progresso científico. Verdade. Testabilidade. Corroboração.

Popper, em sua teoria da ciência, dedicou-se a estudar dois problemas epistemológicos que ele considera como fundamentais²: o problema da indução e o da demarcação científica. O primeiro problema, o da indução, tido por ele como "o problema de Hume", trata "[...] da validade ou verdade de enunciados universais que encontrem base na experiência, tais como: as hipóteses e os sistemas teóricos das ciências empíricas" (POPPER, 1972, p. 28). O segundo, o da demarcaçáo, denominado "problema de Kant", trata da questão de se "[...] estabelecer um critério que nos habilite a distinguir entre as ciências empíricas de uma parte, e a matemática, a lógica, bem como os 'sistemas metafísicos', de outra" (POPPER, 1972, p. 35). Pensamos que da teoria da ciência de Popper emerge um terceiro problema, genuinamente

\footnotetext{
${ }^{1}$ Doutora em Filosofia pela UNICAMP. Professora da Faculdade de Filosofia e do Programa de PósGraduação em Filosofia da Universidade Federal do Pará. E-mail: edias@ufpa.br

${ }^{2}$ Em sua $A$ Lógica da pesquisa científica, no apêndice $*_{i}$, intitulado "Duas notas acerca de indução e demarcação 1933-1934", em sua primeira nota, que é uma "carta ao editor" enviada à direção da revista Ekkenntnis, o problema da indução é apresentado, por Popper, como uma questão preliminar e o da demarcação, como um problema fundamental.
} 
popperiano e não menos fundamental, ou seja, o do progresso do conhecimento, ou, mais especificamente, o do progresso do conhecimento cientifico. Tratase, conforme o próprio filósofo reconhece, de "[...] um dos mais fascinantes problemas da teoria do conhecimento” (POPPER, 1972, p. 541). No prefácio de 1959, da primeira edição inglesa de sua obra A lógica da pesquisa científica, Popper declara que "[...] o problema central da Epistemologia sempre foi e continua a ser o problema do aumento do saber. $\mathrm{O}$ aumento do saber pode ser mais bem analisado se analisarmos o aumento do conhecimento científico" (POPPER, 1972, p. 536). E ainda, em sua Autobiografia intelectual, escreve: "Interessante era o conhecimento problemático, o aumento do conhecimento - a descoberta" (POPPER, 1976, p. 86). Podemos dizer que, além da questão dos limites do conhecimento empírico e do procedimento metodológico da ciência, torna-se pertinente considerar a ideia do progresso da ciência por meio de suas descobertas, como, também, de sua expansão do conhecimento.

O objetivo deste trabalho é analisar a possibilidade do progresso da ciência, na concepção de Popper, já que podemos vislumbrar em suas obras uma preocupaçáa com o avanço do conhecimento científico, com sua expansão. Levamos em conta que, para o filósofo explicar a possibilidade do progresso científico, ele não pode deixar de prescindir da noção de verdade. "A ideia de verdade pode projetar muita luz sobre a ideia do progresso científico" (POPPER, 1982, p. 257). Segundo nossa interpretação, há um vínculo estreito entre a noção de progresso científico e a de verdade em sua metaciência. A ideia de que a ciência progride visando à verdade só irá ser delineada na obra Conjectura e refutaçóes (1963), pois, para estabelecer tal vinculação, Popper precisou, antes, definir a verdade como sendo a meta da ciência, o que só ocorreu, em 1957, quando ele escreveu o artigo intitulado "The aim of science", publicado na revista Ratio.

Em 1934, quando Popper publicou sua obra A Lógica da pesquisa científica, a ciência era definida em termos de regras lógico-metodológicas e não de suas metas. A busca da verdade ainda não era entendida como um fim racional da ciência, porque poderia ser antes uma motivação exclusivamente psicológica dos cientistas. Diz Popper: "A ciência não é um sistema que avance continuamente em direção a um estado de finalidade, ela jamais pode proclamar haver atingido a verdade" (POPPER, 1972, p. 305). E adiante, acrescenta: "[...] o esforço por conhecer e a busca da verdade [...] são os motivos mais fortes da investigação científica” (POPPER, 1972, p. 305). 
Por outro lado, se analisamos as pretensôes do filósofo de traçar os limites do conhecimento empírico, verificamos que estes são definidos em termos de um critério negativo, ou seja, o da falseabilidade, significando, por assim dizer, que as teorias científicas são passíveis de serem falseadas. $\mathrm{Ou}$, em outras palavras, se a observação mostrar que o efeito previsto foi refutado (ou falseado), a teoria deve ser refutada, justamente porque é incompatível com certos resultados observados. Afirma Popper:

[...] não exigirei que um sistema científico seja susceptível de ser dado como válido, de uma vez por todas, em sentido positivo, exigirei, porém que sua forma lógica seja tal que torne possível validá-lo através de recurso a provas empíricas, em sentido negativo, deve ser possível refutar pela experiência, um sistema empírico. (POPPER, 1972, p. 42).

Além da falseabilidade, outro aspecto definidor do caráter empírico e racional da ciência é o progresso contínuo, porque, se ela não progredir, perde necessariamente esse seu aspecto característico (POPPER, 1982, p. 241). Quando Popper fala de progresso do conhecimento, ele náo quer dizer que a ciência avança acumulando experiências perceptuais, ou seja, que a ciência progride adicionando novas experiências ao conhecimento já possuído, mas sim que o crescimento do conhecimento implica substituição de teorias científicas por outras melhores ou mais satisfatórias (POPPER, 1982, p. 241). Faz-se necessário, então, esclarecer que critério deve ser utilizado para se fazer essa substituição, ou melhor, que parâmetros devemos levar em conta para considerar uma teoria preferível em face de outra competidora.

Em sua obra A Lógica da pesquisa cientifica, Popper toma o potencial de falseabilidade, que é o seu critério de demarcação científica, para balizar a definição de um critério de progresso, o qual mais tarde ele denominará "adequação relativa potencial", ou simplesmente "potencial" (POPPER, 1982, p. 241). Esse critério tornará compreensível a possibilidade de escolha racional entre teorias competidoras. Nesse sentido, para que uma teoria represente uma descoberta nova, ou um passo à frente em relação a sua concorrente, é necessário que tenha um maior conteúdo empírico que seja mais consistente, do ponto de vista lógico, e que tenha uma maior capacidade explicativa e poder de previsão (POPPER, 1982, p. 243).

De acordo com esse critério de "adequação relativa ou potencial" (progresso potencial), é possível decidir se uma teoria nova se mostrará melhor do que sua competidora, antes de tê-la submetido a testes empíricos. Em outras 
palavras, podemos julgar se uma teoria representa um avanço em relação a sua antecessora, tendo por base o seu conteúdo empírico (explicativo) e o seu poder preditivo, o qual deverá ser maior que o de sua concorrente, podendo, assim, ser testada de forma mais rigorosa pelo confronto dos fatos previstos com as observaçôes. A melhor teoria deverá, portanto, apresentar um nível de universalidade maior que o de sua competidora.

A ciência física progride, assim, substituindo teorias de um menor nível de universalidade por teorias de um nível mais elevado. Trata-se, pois, de um progresso em sentido "indutivo" (POPPER,1972, p. 303). Mas, Popper, ao defender o progresso nesses termos, não estaria argumentando em favor do procedimento indutivo que ele próprio criticou? Muito embora esse avanço caminhe no sentido indutivo, ele não consiste necessariamente em uma sequência de inferências indutivas. Esse avanço é explicado em termos de testabilidade e corroborabilidade. A teoria corroborada, só poderá ser substituída por outra que tenha um maior nível de universalidade, isto é, que tenha sido mais bem testada e que possa abranger a teoria anteriormente estabelecida. Diz o autor:

Uma teoria que mereceu ampla corroboração só pode ceder passo a uma teoria de mais alto grau de universalidade, ou seja, a uma teoria passível de submeter-se a melhores testes e que, além disso, abranja a teoria anterior e bem corroborada -ou, pelo menos, algo que lhe aproxime muito. (POPPER, 1972, p. 303).

Talvez, pela falta de um termo melhor para indicar o sentido desse avanço, Popper o chamou de "indutivo". Contudo, consciente das dificuldades que esse termo encerra, preferiu denominar "[...] essa tendência de avanço em direção a teorias de nível de universalidade sempre mais elevado, como 'quase indutiva" (POPPER, 1972, p. 303). Esse processo "quase indutivo" deve ser entendido nos seguintes termos:

Teorias de algum nível de universalidade são propostas e dedutivamente submetidas a teste; em seguida, são propostas teorias de nível mais alto de universalidade, por sua vez submetidas a testes, com auxílio das que tem o nível anterior de universalidade; e assim por diante. (POPPER, 1972, p. 304).

Por um lado, temos os testes das teorias que se apoiam em uma lógica dedutiva, seguindo um sentido inverso do indutivo, e que partem de 
enunciados universais (leis universais de nível mais alto) para enunciados particulares (de nível mais baixo); por outro, temos o progresso das teorias, seguindo uma ordem cronológica e náo lógica, que vai dos níveis mais baixos de universalidade para os mais elevados.

Popper utiliza-se, dessa maneira, de um critério lógico para ajuizar o progresso que pode ser resumido nos seguintes termos: rejeição de teorias refutadas e aceitação de teorias corroboradas ${ }^{3}$, isto é, de teorias que resistiram a testes severos que tentaram refutá-las. A escolha da melhor teoria, ou seja, daquela que representa um avanço com relação a sua antecessora, é feita tendo por base os testes aos quais as teorias estão sujeitas. A melhor teoria é aquela que se mostrou "[...] capaz de manter-se incólume, resistindo aos testes a que foi submetida" (POPPER, 1972, p. 275).

A teoria que foi corroborada não pode ser dada como definitiva, pois, posteriormente, poderá vir a ser falseada e substituída por outra que resistir às tentativas de falseamento, ao ser submetida aos testes subsequentes. Por conseguinte, todos os sistemas teóricos devem ser susceptíveis desses testes.

Essa forma de definir o progresso, levando-se em conta o processo dedutivo de testes, gera o problema da susceptibilidade de teste ad infinita e a ausência de sistemas teóricos últimos que não requeiram testes. Popper, ao se defrontar com essa dificuldade, admite que os testes não podem se prolongar ad infinitum e que, mais cedo ou mais tarde, teremos de interrompê-los. Popper não discute esse problema, no âmbito de sua obra $A$ Lógica da pesquisa científica, mas simplesmente procura ressaltar que o fato de os testes não poderem se prolongar indefinidamente náo conflita com a exigência de que todo enunciado seja susceptível, em última instância, de teste. Esse problema, no nosso entender, só será resolvido quando a verdade for definida como meta da ciência, já que somente assim será possível reconhecer que, quando um sistema teórico for submetido a testes e corroborado, ele é dado como

\footnotetext{
${ }^{3}$ Popper introduziu o termo corroboração ou grau de corroboração em sua $A$ Lógica da pesquisa científica para indicar o grau em que uma hipótese foi submetida a testes severos, como revelador de sua qualidade. Carnap traduziu "grau de corroboração" por "grau de confirmação". Popper náo gostou da tradução, devido a ela estar associada a expressóes tais como: "tornar firme", "estabelecer firmemente", "colocar além de qualquer dúvida", "provar", "verificar", e manifestou sua insatisfação a Carnap, insistindo no uso do termo "corroboração". Como Carnap recusou sua proposta, acabou acomodando-se a essa terminologia, chegando a usar, em alguns trabalhos o termo "confirmaçáo". Mais tarde, essa expressáo passou a ser utilizada como sinônimo de probabilidade, o que levou Popper a abandoná-la e empregar definitivamente "grau de corroboração", o qual ele considera mais adequado aos propósitos de sua teoria da ciência, na medida em que rejeita a probabilidade.
} 
verdadeiro ou como uma melhor aproximação da verdade, não exigindo mais novos testes, mesmo que provisoriamente.

Todavia, no âmbito de sua obra A lógica da pesquisa cientifica, Popper, ao definir o progresso científico usando o critério lógico de adequação potencial, dispensa o conceito de verdade, porque considera que "[...] é perfeitamente possível argumentar que o critério do progresso científico é intuitivamente satisfatório sem fazer referência à veracidade das teorias" (POPPER, 1982, p. 248). Isso significa dizer que a ciência progride devido a sua capacidade de eliminar os erros, as contradiçóes, e não por ter a veracidade de suas teorias atestada ou de ser direcionada pela verdade. $\mathrm{O}$ autor chega mesmo a ressaltar, nessa obra, que "[...] é possível evitar a utilizaçáo dos conceitos verdadeiro e falso" (POPPER, 1972, p. 300), argumentando que o lugar desses conceitos pode ser ocupado por

[...] considerações lógicas acerca de relaçōes de dedutibilidade. Assim, não precisamos dizer: 'A previsão $p$ é verdadeira contanto que sejam verdadeiro a teoria $t$ e o enunciado básico $b$ '. Em vez disso, podemos dizer que o enunciado $p$ decorre da conjunçáo (não contraditória) de $t$ e $b$. O falseamento de uma teoria pode ser expresso de maneira análoga. Tampouco precisamos dizer que a teoria é 'falsa', mas ao invés, dizer que ela é contraditada por certo conjunto de enunciados básicos já aceitos. (POPPER, 1972, p. 301).

Em outra obra, resume o "assunto essencial" de sua A lógica da pesquisa cientifica nos seguintes termos: "Nunca podemos estabelecer racionalmente a verdade das leis científicas, tudo o que podemos fazer é [...] eliminar as falsas" (POPPER, 1974, p. 396).

A questão que se impóe, por consequência, é: como podemos identificar o erro, as teorias falsas, sem o conceito de verdade, sem que a teoria de Popper acerca do progresso pareça incompleta? Por outro lado, se nos é possível identificar apenas as teorias falsas e as erradas, como podemos falar de progresso? O progresso da ciência seria uma sucessão de teorias falsas? $\mathrm{O}$ próprio Popper reconhece que só a ideia de verdade nos possibilita falar de maneira sensata sobre os erros (POPPER, 1982, p. 255). Mas, entáo, por que dispensa ele o conceito de verdade, em sua obra $A$ Lógica da pesquisa científica, correndo o risco de comprometer sua própria teoria da ciência?

Várias razóes são apresentadas pelo filósofo por ter evitado a utilização do conceito de verdade, nessa obra. Em primeiro lugar, porque a teoria 
aristotélica da verdade como correspondência entre as sentenças e os fatos estava, naquela época, sendo problematizada, por questionar-se como se daria a suposta correspondência, ou melhor, se de fato era possível tal correspondência entre uma sentença e os respectivos fatos. Por outro lado, havia paradoxos e antinomias que brotavam dessa ideia de correspondência (como o paradoxo do mentiroso), os quais a tornavam inconsistente. Em acréscimo, porque, naquela época, surgiram várias tentativas, consideradas insatisfatórias, por Popper, de explicar como se daria a correspondência entre uma sentença e um fato, como, por exemplo, as de Schlick e Wittgenstein. Além disso, havia ainda uma opinião que Popper se achava incapaz de combater, apesar de não concordar com ela, segundo a qual, "[...] se quisermos falar acerca da verdade devemos ser capazes de dar um critério de verdade” (POPPER, 1975, p. 294295). Podemos dizer, por conseguinte, que Popper não relacionou a questão do progresso científico à noção de verdade, em sua obra $A$ Lógica da pesquisa cientifica, porque, quando a escreveu (1934), náo dispunha de uma consistente teoria da verdade.

A mudança de posição do filósofo, acerca da utilização do conceito de verdade, em sua metaciência, ocorreu em 1935, quando ele leu o trabalho de Tarski, intitulado "The concept of truth in formalizaded language". Declara Popper: "Em consequência dos ensinamentos de Tarski, não hesito mais em falar de "verdade e de falsidade" (POPPER, 1972, nota*1, p. 301). E, ao se referir ao progresso científico, deixa clara a razão por que não o relacionou ao conceito de verdade:

Até aqui falei sobre a ciência, seu progresso e critério de progresso, mas não mencionei o conceito de verdade. [...] De fato, antes de me familiarizar com a teoria da verdade de Tarski, acreditava ser mais seguro discutir o critério de progresso sem envolver-me demais com o problema extremamente controvertido relacionado com o emprego da palavra "verdade". (POPPER, 1982, p. 248).

Adiante, acrescenta: "Na minha teoria sobre o progresso científico posso talvez dispensá-la (a verdade) até certo ponto. Depois de Tarski, porém, não encontro nenhuma razão para tentar evitá-la” (POPPER, 1982, p. 251).

De acordo com a leitura de Popper, Tarski teria resolvido o problema que aparentemente se mostrara insolúvel, qual seja, o de explicar a correspondência entre as asserçôes e os fatos e lhe conferir legitimidade 
lógica. ${ }^{4}$ De maneira muito sucinta, podemos dizer que o conceito de verdade de Tarski é metalinguístico e opera sobre uma determinada linguagem-objeto, a qual nos possibilita falar sobre as asserçôes da linguagem objeto e os fatos às quais elas se referem. Somente de posse de uma linguagem que disponha de ambos os meios é que podemos dizer, por exemplo, que o enunciado "a neve é branca é verdadeiro" corresponde aos fatos se e somente se a neve, de fato, for branca. Tarski formulou, assim, uma teoria da verdade objetiva, mostrando que é possível se falar da verdade como correspondência com os fatos, sem termos necessidade de recusar a ideia de realidade exterior. Para tal, empregou uma metalinguagem semântica, que lhe possibilitou reduzir a ideia de correspondência à de "satisfatoriedade" ou de "preenchimento". Quando se consegue satisfazer a necessidade semântica de uma metalinguagem, a correspondência torna-se clara.

Ao contrário das teorias subjetivistas da verdade, como a teoria da evidência e a teoria pragmática, as quais pretendem fornecer um critério de verdade baseado em fontes ou origens das nossas crenças, ou em operaçóes de verificação, ou ainda em algum conjunto de regras de aceitação ou na qualidade das nossas convicçóes subjetivas, a noção objetivista ou absolutista da verdade de Tarski não nos fornece nenhum critério geral de verdade. É nessa ausência de critério que está a grande vantagem dessa teoria objetivista da verdade, que fará com que Popper a aceite e defina como meta da ciência a verdade.

Com a teoria da verdade de Tarski, as ideias de Popper sobre o progresso científico ganham maior clareza e amplitude, pois o filósofo austríaco, tendo superado suas dificuldades iniciais para falar de verdade, no âmbito de sua teoria da ciência, passa a declarar, sem hesitação, que a ciência busca a verdade, ${ }^{5}$ muito embora o cientista não saiba quando encontrá-la por não dispor de um critério para identificá-la, orientando-se apenas pela verdade como uma espécie de "principio regulador", conceito que Popper tomou emprestado de Kant (POPPER, 1982, p. 251).

A verdade é, dessa maneira, um ideal ou meta a ser alcançada que, de alguma forma, guia o processo de investigação. $\mathrm{O}$ cientista sempre busca teorias verdadeiras que melhor correspondam aos fatos. Porém, por outro

\footnotetext{
${ }^{4}$ No entender de Popper, a teoria de Tarski é uma reabilitação e uma reelaboração da teoria aristotélica de que a verdade é correspondência com os fatos (POPPER, 1975, p. 297).

${ }^{5}$ Popper, em sua obra Conjecturas e refutaçôes, reafirma que a meta da ciência é a verdade, nos seguintes termos: "O fato é que também consideramos a ciência uma busca da verdade e, pelo menos desde Tarski, não temos receio de afirmá-lo” (p. 255).
} 
lado, o cientista não pode ter a ilusão de ter a posse da verdade irrefutável (POPPER, 1972, p. 308).

Assim, Popper, ao mesmo tempo em que considera a impossibilidade da conquista segura da verdade de uma teoria, defende igualmente que o objetivo da ciência é a busca reiterada dessa verdade como correspondência com os fatos. Como conciliar, entáo, essas duas ideias que aparentemente parecem inconciliáveis, de modo a esclarecer a possibilidade do progresso em termos da verdade? Para que essas ideias se relacionem de forma coerente, é preciso que o conceito de verdade (tomado como absoluto) opere no processo de conhecimento como um princípio regulador.

O conhecimento científico nunca alcançaria a plena correspondência com os fatos, no sentido de atingir uma verdade irrefutável, mas progrediria tendo em vista esse ideal de correspondência completa com os fatos. Nesse sentido, seria possível considerar que uma teoria corresponde melhor aos fatos que outra.

[...] a ciência busca teorias verdadeiras, embora nunca possamos estar seguros de que uma teoria em particular é verdadeira; por outro lado, a ciência pode progredir (sabendo que progride) formulando teorias que, comparadas com as anteriormente aceitas são descritas como uma melhor aproximação da verdade. (POPPER, 1987, p. 58).

Para definir que teorias seriam melhores que outras, levando em conta sua correspondência com os fatos, Popper utiliza-se do conceito de verossimilhança ou de aproximação da verdade, que pressupóe as noçóes de conteúdo de verdade e de falsidade. Ele sustenta que as consequências lógicas de uma teoria podem ser divididas entre as que são verdadeiras (o conteúdo de verdade da teoria) e as que são falsas (o conteúdo de falsidade). A diferença entre os dois conjuntos de consequências indica-nos a "verossimilhança" da teoria, ou quão perto ela se encontra da verdade. Dadas duas teorias rivais, $A$ e $B$, podemos conjecturar que $A$ possui maior verossimilhança, se acarreta todas as consequências verdadeiras de $B$ e mais algumas, e se náo tiver mais consequências falsas do que B. Desse modo, uma teoria estará mais próxima da verdade que sua concorrente se, e somente se, mais enunciados verdadeiros decorrem dela (seu conteúdo de verdade deve, portanto, ser maior), porém, não mais enunciados falsos (seu conteúdo de falsidade deverá, consequentemente, ser menor) (POPPER, 1982, p. 257). 
Essa tese da aproximação da verdade foi criticada em suas bases internas, na medida em que ela nos conduz à questão de saber se podemos falar em uma melhor correspondência, ou se haveria graus de verdade. Ou, então, se não seria "[...] perigosamente enganoso falar como se a verdade de Tarski se situasse numa espécie de espaço métrico, ou pelo menos topológico, de tal forma que se possa dizer a respeito de duas teorias" (POPPER, 1982, p. 257) que uma se aproxima mais da verdade do que outra. Mesmo consciente dessas dificuldades, Popper náo abre máo do conceito de aproximação da verdade. Diz ele: “[...] acredito que simplesmente náo podemos dispensar algo como a ideia de uma melhor (ou pior) aproximação da verdade. Não há dúvida de que podemos dizer [...], a propósito de uma teoria t2, que ela corresponde melhor aos fatos, ou que parece corresponder melhor a eles do que outra teoria, $t 1$ " (POPPER, 1982, p. 257).

Dessa forma, Popper não abre mão desse conceito, porque ele é importante para sua definição de progresso científico, já que, sem ele, não seria possível determinar, qual teoria - dentre duas teorias concorrentes - estaria mais próxima da verdade.

Assim, para solucionar a questão da possibilidade do progresso, Popper precisou introduzir as ideias de verdade e de aproximação da verdade, no âmbito de sua metaciência. Tais ideias estão intimamente associadas à ideia de testabilidade e corroboração. Se a ciência progride com a eliminação de erros das teorias falsas é porque ela visa não somente à eficácia, mas também, à verdade como padrão a ser alcançado. É a noção de verdade ou de aproximação da verdade que possibilita uma avaliaçáo de teorias concorrentes, permitindo, dessa forma a identificação daquelas que representam um avanço com relação a sua rival, por ter um maior conteúdo de verdade e, consequentemente, por apresentar uma maior aproximaçáo da verdade. 
DIAS, Elizabeth de Assis. Scientific progress and truth in Popper. Trans/Form/Ação, Marília, v. 38, n. 2, p. 163-174, Maio/Ago., 2015.

\begin{abstract}
This paper aims to show that to solve the question of the possibility of scientific progress, Popper had to introduce the idea of truth into his theory of science. This conception of progress, in terms of the notion of truth, was only outlined in the work Conjectures and Refutations (1963). The idea that the goal of science is truth does not appear in his early works. When Popper wrote his The Logic of Scientific Discovery (1934), science was defined in terms of logic-methodological rules, and not of its goals. Scientific progress was conceived based on the notions of testability and corroboration of theories, logical and methodological requirements for a theory to be considered scientific. Popper did not relate the question of scientific progress to notion of truth in this work, because when he wrote it he did not have a consistent theory of truth. It was only after Tarski had written his article on the semantic conception of truth that Popper, based on this conception of truth, could complement his thesis about the progress of science expounded in The Logic of Scientific Discovery with a theory about the content of truth and the approximation to the truth.
\end{abstract}

KEYWORDS: scientific progress. truth. testability. corroboration.

\title{
REFERÊNCIAS
}

POPPER, Karl R. Conjecturas e refutaçôes. Brasília: Editora Universidade de Brasília, 1982. . O Realismo e o objetivo da ciência. Lisboa: Publicaçōes Dom Quixote, 1987. . Conhecimento objetivo. Belo Horizonte: Itatiaia; São Paulo: Ed. da Universidade de São Paulo, 1975

. A lógica da pesquisa científica. São Paulo: Cultrix, 1972. . Autobiografia intelectual. São Paulo: Cultrix, 1976.

. A sociedade aberta e seus inimigos. Belo Horizonte: Itatiaia, 1974. 2v.

.The aim of Science. Ratio, I, p. 24-35. Reimpresso no seu [1972]. p. 180-191.

TARSKI, A. A concep̧̧ão semântica da verdade. São Paulo: Editora UNESP, 2007.

Recebido / Received: 01/10/2014

Aprovado / Approved: 10/11/2014 